\title{
A Trend Analysis of the Prevalence, Awareness, Treatment, and Control of Hypertension by Age Group
}

\author{
Jong Youn Moon, Kwan Jun Park, Young Hwangbo, Mee Ri Lee, Byoung In Yoo, Jong Hye Won, Yoon Hyung Park \\ Department of Preventive Medicine, Soonchunhyang University College of Medicine, Cheonan, Korea
}

Objectives: We examined the trends in prevalence, awareness, treatment, and control of hypertension in Korea as a basis for improving hypertension control programs.

Methods: 12598 participants of the Korean National Health and Nutrition Examination Survey were included in this study. Weighted linear regression to test time trends from 2007 to 2011 was performed.

Results: The prevalence of hypertension was $20.7 \%$ in $2007,29.4 \%$ in 2009 , and $26.2 \%$ in 2011 . Awareness of hypertension was $64.8 \%$ in 2007 and $61.1 \%$ in 2011. Awareness in those aged 65 and over was greater than in younger groups (age 19 to 44 and 45 to 64 ; $p<0.001)$. The treatment rates were $58.4 \%$ in 2007 and 56.8\% in 2011. The treatment rate was greater for those 65 and over than for younger age groups $(p<0.001)$. The percentage of controlled hypertension was $37.6 \%$ in 2011 . The percentage of controlled hypertension in those 65 and over was higher than in younger age groups $(p<0.001)$. The treatment-control rates were $65.9 \%$ in 2007 and $67.7 \%$ in 2011. The prevalence of hypertension was higher in the males $(p<0.001)$, while the awareness $(p<0.001)$, treatment $(p<0.001)$, and control $(p<0.001)$ rates were higher in the females.

Conclusions: The prevalence of hypertension was increasing and the hypertension awareness, treatment, and control rates were low in younger age groups and males.

Key words: Prevalence, Awareness, Therapeutics, Prevention \& control, Hypertension, Korean National Health and Nutrition Examination Survey

\section{INTRODUCTION}

The prevalence of cardiovascular disease (CVD) has been continuously increasing due to population aging, and changes in consumption and lifestyle patterns [1]. This global trend is

Received: September 27, 2013; Accepted: October 21, 2013

Corresponding author: Yoon Hyung Park, MD, PhD

31 Suncheonhyang 6-gil, Dongnam-gu, Cheonan 330-930, Korea

Tel: +82-41-570-2483, Fax: +82-41-575-2406

E-mail: parky@sch.ac.kr

This is an Open Access article distributed under the terms of the Creative Commons Attribution Non-Commercial License (http://creativecommons.org/licenses/by$\mathrm{nc} / 3.0 /$ ) which permits unrestricted non-commercial use, distribution, and reproduction in any medium, provided the original work is properly cited. also apparent in the Republic of Korea, reflected in the increasing mortality and personal cost to treat and manage CVD [2]. As the prevalence of chronic conditions is increasing, the risk of mortality due to chronic conditions, especially hypertension, and associated complications are rising in numbers along with them [3-5]. Cerebrovascular disease caused 50.7 deaths per 100000 members of the population in 2011, followed by 49.8 deaths by CVD and 21.5 deaths caused by diabetes [6].

Furthermore, the leading global risks for mortality are high blood pressure (BP, responsible for $13 \%$ of deaths globally), tobacco use (9\%), high blood glucose (6\%), physical inactivity (6\%), and overweight and obesity (5\%) [7]. In 2011, the Political Declaration on Noncommunicable Diseases was adopted by the UN General Assembly [8]. The declaration focused on 
the risk factors and national systems response to 4 noncommunicable diseases (NCDs): CVD, diabetes, cancer, and chronic respiratory disease. The UN target is $25 \%$ reduction in relative mortality from NCDs by 2025 [9]. To control those burdens, strict control of BP is required. According to the Joint National Committee 7 guideline, for every $20 \mathrm{mmHg}$ increase in systolic or $10 \mathrm{mmHg}$ in diastolic $\mathrm{BP}$, there is a doubling of mortality from both ischemic heart disease and stroke [10]. Other studies on the elderly have also noted that improving control of hypertension is important to reduce the risk for CVDs [11,12]. Thus many programs to control hypertension, such as screening and education to reduce its complications, have been implemented [13-15].

Our study examined changes in the prevalence, awareness, treatment, and control of hypertension for all adults combined and for subsets by age and sex across Korean National Health and Nutrition Examination Survey (KNHANES) 2007to 2011 data with the aim of gathering information for improving hypertension control programs.

\section{METHODS}

Data from the 2007 to 2011 KNHANES, conducted by the Korea Centers for Disease Control and Prevention (KCDC), was used in this study. The KNHANES participants were selected using stratified, multistage probability sampling of the non-institutionalized population. All adults provided written informed consent. In data analysis method and presenting results, 'US trends in prevalence, awareness, treatment, and control of hypertension, 1988-2008' [16] were used.

\section{Definitions}

In the KNHANES 2007 to 2011, BP was measured by physicians trained in the method using a mercury sphygmomanometer (Baumanometer; WA Baum Co., New York, NY, USA) and appropriately sized arm cuffs after the study participants rested 5 minutes seated. Individuals without a recorded BP were excluded. In determining the mean BP for individuals, the first BP was used if only 1 measurement was obtained. The second $\mathrm{BP}$ was used if 2 readings were taken; the second and third values were averaged when available. Hypertension was defined as a mean systolic BP of at least $140 \mathrm{mmHg}$, mean diastolic BP of at least $90 \mathrm{mmHg}$, or both, and/or confirming that a participant was currently taking prescription medication to lower BP. Awareness of hypertension was determined by pa- tients with hypertension responding affirmatively to the question, "Have you ever been diagnosed with hypertension by a doctor?"Treatment of hypertension was established by participants responding yes to the question, "Are you currently using antihypertensive drugs?" Control of hypertension was defined as BP under $120 / 80 \mathrm{mmHg}$ with or without treatment. Treatment-control of hypertension was defined as BP under 120/80 $\mathrm{mmHg}$ with treatment. For calculating awareness, treatment, and control, the participants were stratified into the following age groups: 19 to 44 years, 45 to 64 years, and 65 years and above.

\section{Data Analysis}

The KNHANES Analytic and Reporting Guidelines were followed. SAS version 9.3 (SAS Inc., Cary, NC, USA) was used to account for the KNHANES complex sampling design, to estimate mean values and percentages, and to calculate $95 \%$ confidence intervals $(\mathrm{Cls})$. To calculate prevalence, survey commands were used and for calculating awareness, treatment, and control, additional weights were calculated because hypertension prevalence varies by age group. Weighted linear regression to test time trends from 2007 to 2011 was performed using estimated mean values or percentages as dependent variables. Reciprocals of variances were used as weights. Time was an independent and continuous variable in the regression models for all of the patients with hypertension combined and each subgroup. Statistical significance was defined by $p<0.05$. Data are presented as means and $95 \% \mathrm{Cls}$.

\section{RESULTS}

\section{All Adults}

The mean age increased over time between 2007 and 2011 ( $p$ for trend $=0.008)$ (Table 1). The mean systolic BP $(p<0.001)$ and mean diastolic BP $(p=0.005)$ both increased over time.

The proportion of stage 1 and 2 hypertension (stage 1: systolic/diastolic BP, 140-159/90-99 mmHg; stage 2: systolic/diastolic BP, over 160/over $100 \mathrm{mmHg}$ ) increased from 9.9\% (95\% $\mathrm{Cl}, 8.3 \%$ to $11.5 \%)$ to $12.5 \%(95 \% \mathrm{Cl}, 11.3$ to 13.6$)$ from 2007 to 2011 ( $p$ for trend $<0.001$ ) and $3.1 \%(95 \% \mathrm{Cl}, 2.2$ to 3.9$)$ to $3.9 \%$ ( $95 \% \mathrm{Cl}, 3.3$ to 4.5 ) from 2007 to 2011 ( $p$ for trend $=0.002$ ) (Table 1). The mean body mass index $\left(\mathrm{BMl}, \mathrm{kg} / \mathrm{m}^{2}\right)$ increased from 2007 to 2011 ( $p$ for trend <0.001). The proportions of normal body weight (18.5 $\leq \mathrm{BMI}<25.0, p=0.88)$ and obesity (BMI $\geq$ 25.0, $p=0.94)$ did not change. The prevalence of hypertension 


\section{Journal of}

Table 1. Characteristics of all adult participants in the Korean National Health and Nutrition Examination Survey 2007 to 2011

\begin{tabular}{|c|c|c|c|c|c|c|}
\hline Characteristics & $2007(n=3020)$ & $2008(n=6772)$ & $2009(n=7504)$ & $2010(n=6303)$ & $2011(n=6150)$ & $p$ for trend \\
\hline Mean age (y) & $44.1(43.1,45.2)$ & $44.4(43.6,45.2)$ & $44.8(44.0,45.6)$ & $45.1(44.2,46.1)$ & $45.7(44.8,46.6)$ & 0.008 \\
\hline \multicolumn{7}{|l|}{$\operatorname{Sex}(\%)$} \\
\hline Men & $49.5(47.9,51.1)$ & $49.5(48.3,50.6)$ & $49.5(48.5,50.6)$ & $49.1(47.9,50.3)$ & $49.5(48.2,50.8)$ & \multirow[t]{2}{*}{0.98} \\
\hline Women & $50.5(48.9,52.1)$ & $50.5(49.4,51.7)$ & $50.5(49.4,51.5)$ & $50.9(49.7,52.1)$ & $50.5(49.2,51.8)$ & \\
\hline \multicolumn{7}{|l|}{ Mean BP (mmHg) } \\
\hline Systolic & $115.6(114.3,116.9)$ & $114.3(113.5,115.1)$ & $119.0(118.3,119.7)$ & $119.6(118.8,120.4)$ & $117.6(116.9,118.4)$ & $<0.001$ \\
\hline Diastolic & $76.0(75.3,76.7)$ & $74.8(74.3,75.4)$ & $78.3(77.8,78.8)$ & $77.2(76.7,77.8)$ & $76.1(75.7,76.5)$ & 0.005 \\
\hline \multicolumn{7}{|l|}{$\mathrm{BP}(\mathrm{mmHg}, \%)$} \\
\hline$\geq 160 / \geq 100$ & $3.1(2.2,3.9)$ & $2.6(2.1,3.1)$ & $5.3(4.5,6.0)$ & $4.6(3.9,5.3)$ & $3.9(3.3,4.5)$ & 0.002 \\
\hline 140-159/90-99 & $9.9(8.3,11.5)$ & $10.8(9.8,11.7)$ & $16.6(15.4,17.8)$ & $16.2(14.9,17.6)$ & $12.5(11.3,13.6)$ & $<0.001$ \\
\hline $120-139 / 80-89$ & $32.7(30.2,35.2)$ & $28.4(27.0,29.9)$ & $33.5(32.1,34.9)$ & $32.6(30.9,34.3)$ & $33.2(31.6,34.8)$ & 0.10 \\
\hline$<120 /<80$ & $54.4(51.1,57.7)$ & $58.2(56.1,60.3)$ & $44.6(42.7,46.5)$ & $46.6(44.2,48.9)$ & $50.5(48.5,52.5)$ & $<0.001$ \\
\hline Mean BMI & $23.6(23.5,23.8)$ & $23.6(23.4,23.7)$ & $23.6(23.5,23.7)$ & $23.6(23.5,23.7)$ & $23.7(23.5,23.8)$ & $<0.001$ \\
\hline \multicolumn{7}{|l|}{ BMI (\%) } \\
\hline$<18.5$ & $4.6(3.6,5.7)$ & $5.0(4.3,5.7)$ & $4.8(4.2,5.4)$ & $4.8(4.2,5.5)$ & $5.0(4.3,5.8)$ & 0.66 \\
\hline $18.5-24.9$ & $63.3(61.1,65.4)$ & $63.9(62.4,65.4)$ & $63.3(61.9,64.7)$ & $63.9(62.4,65.4)$ & $63.1(61.5,64.6)$ & 0.88 \\
\hline$\geq 30.0$ & $32.1(29.9,34.3)$ & $31.1(29.6,32.6)$ & $31.9(30.6,33.3)$ & $31.3(29.8,32.8)$ & $31.9(30.3,33.5)$ & 0.94 \\
\hline Diabetes (\%) & $5.9(4.8,7.0)$ & $6.1(5.5,6.8)$ & $6.1(5.4,6.7)$ & $6.3(5.6,7.0)$ & $6.6(5.8,7.4)$ & 0.25 \\
\hline
\end{tabular}

Values are presented as mean or \% (95\% confidence interval) by year.

$\mathrm{BP}$, blood pressure; BMI, body mass index.

'Data are weighted based on a Korean population.

${ }^{2}$ Weighted linear regression was used for calculating $p$ for trends.

Table 2. Characteristics of adult participants with hypertension in the Korean National Health and Nutrition Examination Survey 2007 to $2011^{1}$

\begin{tabular}{|c|c|c|c|c|c|c|}
\hline Characteristics & $2007(n=764)$ & $2008(n=1837)$ & $2009(n=2486)$ & $2010(n=2138)$ & $2011(n=1967)$ & $p$ for trend ${ }^{2}$ \\
\hline Mean age (y) & $57.7(56.2,59.3)$ & $56.5(55.6,57.5)$ & $55.4(54.3,56.5)$ & $56.3(55.2,57.4)$ & $57.2(56.1,58.3)$ & 0.69 \\
\hline \multicolumn{7}{|l|}{ Sex $(\%)$} \\
\hline Women & $48.7(43.8,53.6)$ & $47.6(45.3,49.9)$ & $42.2(40.1,44.4)$ & $44.1(41.5,46.6)$ & $44.2(41.8,46.7)$ & 0.01 \\
\hline \multicolumn{7}{|l|}{ Mean BP (mmHg) } \\
\hline \multicolumn{7}{|l|}{$\mathrm{BP}(\mathrm{mmHg}, \%)$} \\
\hline$\geq 160 / \geq 100$ & $14.9(11.5,18.2)$ & $11.5(9.4,13.7)$ & $18.0(15.8,20.2)$ & $15.7(13.5,17.8)$ & $14.8(12.6,17.1)$ & 0.37 \\
\hline 140-159/90-99 & $47.5(43,52.1)$ & $47.4(44.6,50.1)$ & $56.5(53.9,59)$ & $55.4(52.4,58.4)$ & $47.6(44.5,50.7)$ & 0.24 \\
\hline 120-139/80-89 & $28.9(24.4,33.5)$ & $26.4(24,28.7)$ & $19.7(17.7,21.7)$ & $22.5(20.1,24.8)$ & $26.3(23.9,28.7)$ & 0.14 \\
\hline $18.5-24.9$ & $45.8(42,49.6)$ & $48.7(45.8,51.5)$ & $50.7(48.2,53.3)$ & $51.4(48.5,54.3)$ & $50.2(47.5,52.9)$ & 0.03 \\
\hline$\geq 30.0$ & $53.2(49.3,57.1)$ & $49.0(46.1,51.8)$ & $47.5(45.0,50.0)$ & $47.0(44.0,50.0)$ & $47.4(44.7,50.2)$ & 0.01 \\
\hline Diabetes (\%) & $14.6(11.7,17.5)$ & $15.0(13.1,16.8)$ & $13.0(11.5,14.5)$ & $12.6(11.1,14)$ & $15.6(13.7,17.6)$ & 0.97 \\
\hline
\end{tabular}

Values are presented as mean or \% (95\% confidence interval) by year. $\mathrm{BP}$, blood pressure; $\mathrm{BMI}$, body mass index.

'Data are weighted based on a Korean population.

${ }^{2}$ Weighted linear regression was used for calculating $p$ for trends. 
Table 3. Prevalence, awareness, treatment, and control of hypertension in the Korean National Health and Nutrition Examination Survey 2007 to 2011

\begin{tabular}{|c|c|c|c|c|c|c|}
\hline & 2007 & 2008 & 2009 & 2010 & 2011 & $p$ for trend \\
\hline Prevalence $\%^{2}$ & $20.7(18.5,23.0)$ & $22.7(21.3,24.1)$ & $29.4(27.7,31)$ & $29.3(27.5,31.1)$ & $26.2(24.6,27.7)$ & $<0.001$ \\
\hline Awareness $\%^{3}$ & $64.8(59.8,69.8)$ & $65(62.1,67.8)$ & $52.4(49.4,55.4)$ & $56.6(53.1,60.2)$ & $61.1(58.2,64.0)$ & 0.02 \\
\hline Treatment $\%^{3}$ & $58.4(53.1,63.6)$ & $58.8(55.7,61.9)$ & $47.4(44.2,50.5)$ & $52.2(48.9,55.6)$ & $56.8(53.9,59.8)$ & 0.20 \\
\hline Treatment-control $\%^{3}$ & $65.9(58.6,73.3)$ & $70.1(66.5,73.8)$ & $54.0(50.3,57.7)$ & $56.2(52.5,59.9)$ & $67.7(64.2,71.2)$ & 0.28 \\
\hline Control $\%^{3}$ & $37.6(32.4,42.8)$ & $41.1(37.8,44.4)$ & $25.5(22.8,28.2)$ & $28.9(26.3,31.5)$ & $37.6(34.7,40.4)$ & 0.08 \\
\hline
\end{tabular}

Values are presented as mean or \% (95\% confidence interval) by years.

'Weighted linear regression was used for calculating $p$ for trends.

${ }^{2}$ Data are weighted based on a Korean population.

${ }^{3}$ Additional weights are calculated because the prevalence of hypertension is different by years.

increased from $20.7 \%(95 \% \mathrm{Cl}, 18.5 \%$ to $23.0 \%)$ in 2007 to $26.2 \%(95 \% \mathrm{Cl}, 24.6 \%$ to $27.7 \%)$ in 2011 ( $p<0.001)$ (Table 2).

\section{All Patients With Hypertension}

Among the participants with hypertension, the mean age $(p=0.69)$ did not change (Table 3 ). The proportion of men increased from $51.3 \%$ (95\% Cl, $46.4 \%$ to $56.2 \%$ ) in 2007 to $55.8 \%$ ( $95 \% \mathrm{Cl}, 53.3 \%$ to $58.2 \%)$ in 2011 ( $p=0.01)$. The mean systolic BP did not change $(p=0.42)$, but the mean diastolic pressure decreased from $86 \mathrm{mmHg}(95 \% \mathrm{Cl}, 84.8$ to $87.1 \mathrm{mmHg})$ to 84.1 $\mathrm{mmHg}(95 \% \mathrm{Cl}, 83.3$ to $84.8 \mathrm{mmHg})$ from 2007 to 2011 ( $p=$ $0.05)$. The proportion of stage I $(p=0.24)$ and stage II $(p=0.37)$ hypertension, prehypertension $(p=0.14)$, and normal $\mathrm{BP}(p=$ 0.35 ) did not change over the 5 years. The mean BMI decreased from $25.3(95 \% \mathrm{Cl}, 25.1$ to 25.6$)$ to $24.9(95 \% \mathrm{Cl}, 24.7$ to 25.1$)$ from 2007 to $2011(p=0.02)$. The proportion of participants with normal body weight increased $(p=0.03)$, while the proportion of obese participants decreased $(p=0.01)$.

The prevalence of hypertension increased from $20.7 \%$ (95\% $\mathrm{Cl}, 18.5 \%$ to $23.0 \%$ ) to $26.2 \%$ ( $95 \% \mathrm{Cl}, 24.6 \%$ to $27.7 \%$ ) from 2007 to 2011 ( $p<0.001$ ) (Table 2). The proportion of participants who were diagnosed with hypertension by a doctor (awareness rate) decreased over the 5 years $(p=0.02)$. The proportion of patients who were treated for hypertension (treatment rate) initially decreased from $58.4 \%$ (2007) to $47.4 \%$ (2009). However, it then increased to $56.8 \%$ in 2011 , but the trend remained unchanged over the entire 5 years $(p=0.20)$. The proportions of patients being treated or whose BP was already normal (treatment-control rate) were $65.9 \%$ (2007), 70.1\% (2008), $54.0 \%$ (2009), 56.2\% (2010), and 67.7\% (2011), but the trend was unchanged $(p=0.08)$. The proportions of all of the patients (treated or not) whose BP was normal (control rate) were 37.6\% (2007), 41.1\% (2008), 25.5\% (2009), 28.9\% (2010), and 37.6\%
(2011), but the trend was unchanged $(p=0.28)$.

\section{Epidemiology of Hypertension by Age Group}

The prevalence of hypertension increased during 2007 to 2011 in individuals aged 19 to 44 years $(p<0.001), 45$ to 64 years $(p=0.002)$, and 65 years and over $(p<0.01)$ (Figure $1 \mathrm{~A})$. However, while the awareness rate increased in those aged 65 years and over $(p<0.01)$, it decreased in those aged 19 to 44 years $(p<0.01)$ and 45 to 64 years $(p<0.01)$ over the course of the 5 years (Figure 1B). The treatment rate of hypertension increased in those 65 years and over $(p<0.01)$, but it decreased in those aged 19 to 44 years $(p<0.01)$, and was unchanged in those aged 45 to 64 during the 5 years (Figure 1C). The treatment-control rate did not change over time in any of the age groups. In addition, there were no differences between those 65 years and above and those 19 to 44 years $(p=0.07)$ and 45 to 64 years ( $p=0.07$ ) (Figure 1D). The control rate decreased in those aged 19 to $44(p<0.01)$ and 45 to $64(p=0.03)$, but it did not change in those aged 65 years and above during the 5 years $(p=0.15)$ (Figure $1 \mathrm{E})$.

\section{Epidemiology of Hypertension by Sex}

The prevalence of hypertension increased from 2007 to 2011 in both the males $(p<0.01)$ and the females $(p<0.01)$ (Table 4$)$. Furthermore, the prevalence was higher in the males $(p<0.01)$. The awareness rate decreased with time in the men $(p<0.01)$ but not the women $(p=0.58)$ and was greater in the women than the men $(p<0.01)$. The treatment rate did not change in the women $(p=0.91)$ or men $(p=0.22)$ and was higher in the women than the men $(p<0.01)$. The treatment-control rate did not change in the women $(p=0.10)$ or men $(p=0.98)$. The control rate in the women $(p=0.91)$ and men $(p=0.22)$ did not change over time, and there was no difference between the two groups. 

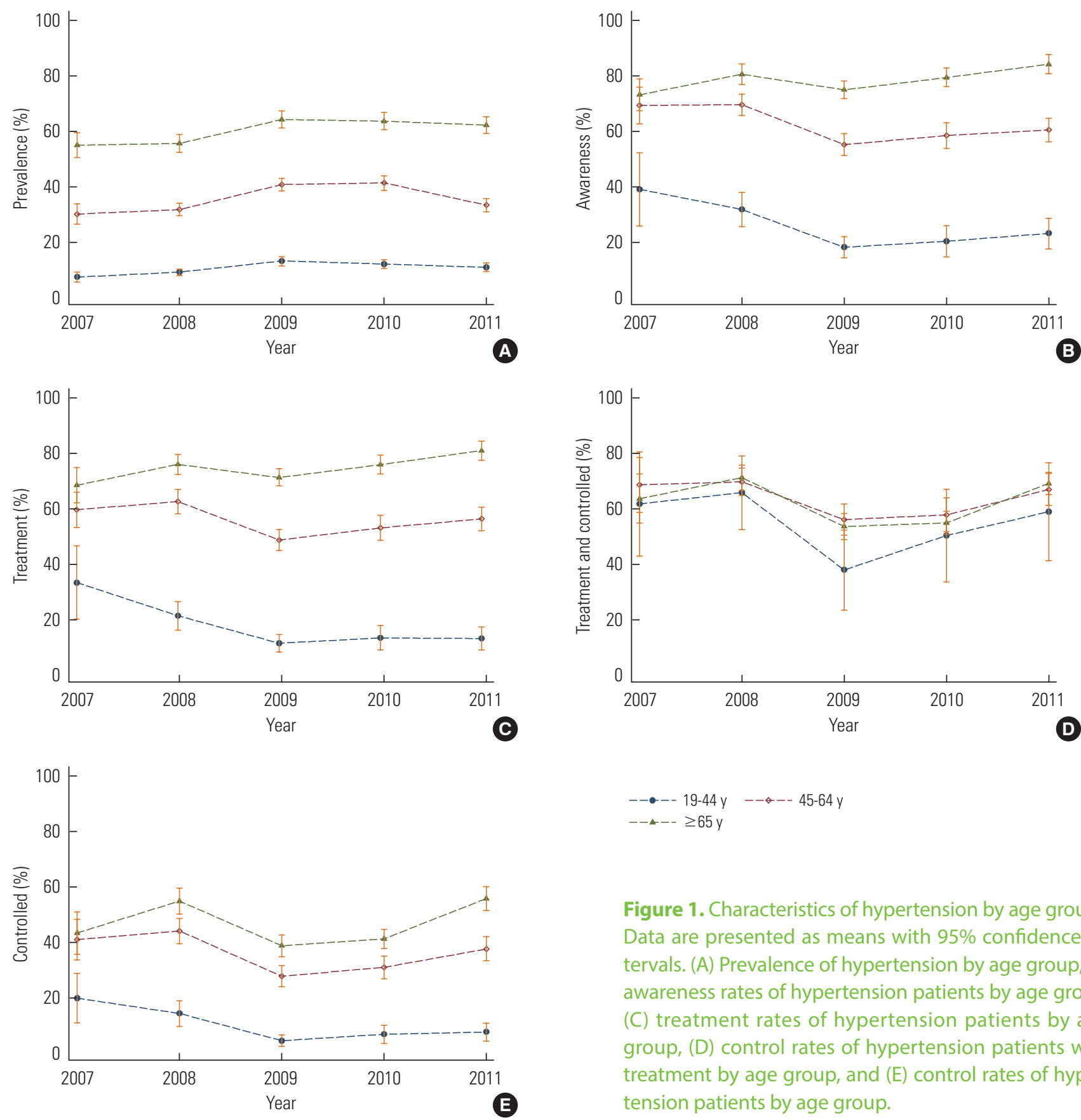

$\begin{array}{ll}---19-44 \text { y } & -----45-64 \text { y } \\ -----265 y & \end{array}$

\section{DISCUSSION}

In the representative sample of Korean adults who participated in the KNHANES in 2007 to 2011, the mean BMI and diastolic BP increased over time. However, in the hypertensive patients, the BMI and diastolic BP decreased, but the prevalence of hypertension was $20.7 \%$ in $2007,29.4 \%$ in 2009 , and $26.2 \%$ in 2011. In a similar study in the US, the prevalence of hypertension was $29.5 \%$ in 2009 to 2010 [17]. In another study in

Korea in 2004, the prevalence of hypertension was 28.3\% [18], and in yet another study in a rural area of Korea in 2000, the prevalences of hypertension in males and females were $18.1 \%$ and $15.5 \%$, respectively [19]. Therefore, it is not safe to conclude that the prevalence of hypertension changed as rapidly in one year as the present study found, but it does seem that there is a trend of increasing prevalence of hypertension. The prevalence of hypertension increased in all age groups. However, the awareness and control rate decreased all age groups ex- 
Table 4. Prevalence, awareness, treatment, and control of hypertension by sex in the Korean National Health and Nutrition Examination Survey 2007 to 2011

\begin{tabular}{|c|c|c|c|c|c|c|c|}
\hline & Sex & 2007 & 2008 & 2009 & 2010 & 2011 & $p$ for trend ${ }^{1}$ \\
\hline \multirow[t]{2}{*}{ Prevalence $\%^{2}$} & Male & $21.5(18.3,24.7)$ & $24.0(22.2,25.8)$ & $34.2(32.1,36.3)$ & $33.4(30.9,35.9)$ & $29.5(27.4,31.6)$ & $<0.001$ \\
\hline & Female & $20.0(17.3,22.7)$ & $21.4(19.8,23.0)$ & $24.6(22.6,26.6)$ & $25.4(23.3,27.4)$ & $22.9(21.1,24.8)$ & 0.006 \\
\hline \multirow[t]{2}{*}{ Awareness $\%^{3}$} & Male & $55.6(48.4,62.8)$ & $56.1(52.2,60.1)$ & $43.9(40.3,47.5)$ & $45.3(40.9,49.6)$ & $50.8(46.8,54.9)$ & 0.02 \\
\hline & Female & $74.4(69.4,79.5)$ & $74.6(71.1,78.2)$ & $64.1(60.5,67.7)$ & $71.1(67.4,74.7)$ & $73.8(70.1,77.6)$ & 0.58 \\
\hline \multirow[t]{2}{*}{ Treatment $\%{ }^{3}$} & Male & $48.7(41.4,56.0)$ & $47.6(43.4,51.9)$ & $37.8(34.3,41.4)$ & $40.1(36.1,44.1)$ & $46.1(42.1,50.2)$ & 0.22 \\
\hline & Female & $68.5(62.7,74.2)$ & $71(67.3,74.6)$ & $60.4(56.5,64.2)$ & $67.6(63.9,71.4)$ & $70.1(66.3,74.0)$ & 0.91 \\
\hline \multirow[t]{2}{*}{ Treatment-control $\%^{3}$} & Male & $62.0(52.0,72.0)$ & $68.2(62.1,74.3)$ & $53.0(47.5,58.5)$ & $59.3(54.0,64.6)$ & $65.6(60.3,70.9)$ & 0.98 \\
\hline & Female & $68.8(60.6,77.0)$ & $71.6(67.9,75.3)$ & $54.9(50.9,58.8)$ & $53.8(49.2,58.5)$ & $69.4(65.4,73.5)$ & 0.10 \\
\hline \multirow[t]{2}{*}{ Control $\%^{3}$} & Male & $29.5(23.1,35.8)$ & $32.3(28.0,36.6)$ & $20.0(17.1,22.9)$ & $23.4(20.3,26.5)$ & $29.4(25.8,32.9)$ & 0.33 \\
\hline & Female & $46.2(39.9,52.4)$ & $50.8(46.7,54.8)$ & $33.1(29.8,36.3)$ & $35.9(32.1,39.6)$ & $47.9(44.0,51.8)$ & 0.17 \\
\hline
\end{tabular}

Values are presented as mean or $\%$ ( $95 \%$ confidence interval) by year.

${ }^{1}$ Weighted linear regression was used for calculating $p$ for trends.

${ }^{2}$ Data are weighted based on a Korean population.

${ }^{3}$ Additional weights are calculated because the prevalence of hypertension is different by years.

cept those aged 65 and over. The treatment rate decreased in the 19 to 44 age group. The prevalence of hypertension in the younger age group increased but the awareness, treatment, and control rates were lower than in the older age groups. Therefore, policies targeting younger people, such as education in schools and workplaces, are needed. One systematic review has addressed which educational and organizational interventions are effective in reaching BP goals and reducing mortality [20].

The treatment-control rate was $54 \%$ to $70.1 \%$ and it did not change over time. This shows that over $30 \%$ of the hypertension patients were not controlled even if they were using antihypertensive drugs. The first explanation could be that resistant hypertension, in which the BP remains above the goal in spite of the concurrent use of 3 antihypertensive agents of different classes, is highly prevalent in older age [21]. Second, compliance with treatment might be low even if the participants answered that they were taking antihypertensive medicine. Third, physicians differ in the goals they set for controlling hypertension.

The limitations of our study are as follows: first, a short period during which to examine the trends of hypertension. The KNHANES has been conducted since 1998. However, the survey questions and physical examination methods were different at first. The circulating survey has been used only since 2007. Because we wanted to examine the trends of hypertension, consistency of data was important. Therefore, data before 2007 were not used in our analysis. Second, people who were under age 19 and in hospitals and nursing homes were omitted. Third, the misclassification of participants could have occurred during the survey.

In conclusion, this was the first study using KNHANES data to examine trends in hypertension awareness, treatment, and control rates by age group and sex. The prevalence of hypertension was found to be increasing and the hypertension awareness, treatment, and control rates were low in the younger age group and male group. Therefore, efforts to detect people with high BP and policies focusing on the hypertension of younger age groups is needed to prevent the complications of hypertension.

\section{CONFLICT OF INTEREST}

The authors have no conflicts of interest with the material presented in this paper.

\section{REFERENCES}

1. World Health Organization. The global burden of disease. Geneva: World Health Organization; 2008, p. 25-26.

2. Chung HG, Kang YK. 2009 National health insurance statistical yearbook. Seoul: National Health Insurance Corporation; 2010, p. 351-598.

3. Vasan RS, Larson MG, Leip EP, Evans JC, O'Donnell CJ, Kannel WB, et al. Impact of high-normal blood pressure on the risk of cardiovascular disease. N Engl J Med 2001;345(18):1291-1297.

4. Khosla N, Kalaitzidis R, Bakris GL. The kidney, hypertension, and remaining challenges. Med Clin North Am 2009;93(3):697-715. 
5. Wong ND, Thakral G, Franklin SS, L'Italien GJ, Jacobs MJ, Whyte $\mathrm{JL}$, et al. Preventing heart disease by controlling hypertension: impact of hypertensive subtype, stage, age, and sex. Am Heart J 2003;145(5):888-895.

6. Statistics Korea. Mortality statistics 2011 [cited 2013 Sep 23]. Available from: http://kostat.go.kr/portal/korea/kor_nw/2/6/2/ index.board? bmode $=$ read $\&$ aSeq $=260046$.

7. Epping-Jordan J. Innovate care for chronic conditions: building blocks for action global report. Geneva: World Health Organization; 2002, p. 12-13.

8. Alleyne G, Binagwaho A, Haines A, Jahan S, Nugent R, Rojhani $A$, et al. Embedding non-communicable diseases in the post2015 development agenda. Lancet 2013;381(9866):566-574

9. World Health Organization. NCD global monitoring framework [cited 2013 Sep 23]. Available from: http://www.who. int/nmh/global_monitoring_framework/en/.

10. Chobanian AV. The seventh report of the Joint National Committee on Prevention, Detection, Evaluation, and Treatment of High Blood Pressure. Bethesda: National Institutes of Health; National Heart, Lung, and Blood Institute; 2004, p. 9-10.

11. Wolf-Maier K, Cooper RS, Kramer H, Banegas JR, Giampaoli S, Joffres MR, et al. Hypertension treatment and control in five European countries, Canada, and the United States. Hypertension 2004;43(1):10-17.

12. Rashid P, Leonardi-Bee J, Bath P. Blood pressure reduction and secondary prevention of stroke and other vascular events: a systematic review. Stroke 2003;34(11):2741-2748.

13. Fortmann SP, Winkleby MA, Flora JA, Haskell WL, Taylor CB. Effect of long-term community health education on blood pressure and hypertension control. The Stanford Five-City Project. Am J Epidemiol 1990;132(4):629-646.
14. Kotchen JM, McKean HE, Jackson-Thayer S, Moore RW, Straus $\mathrm{R}$, Kotchen TA. Impact of a rural high blood pressure control program on hypertension control and cardiovascular disease mortality. JAMA 1986;255(16):2177-2182.

15. Iso H, Shimamoto T, Naito $Y$, Sato S, Kitamura A, lida M, et al. Effects of a long-term hypertension control program on stroke incidence and prevalence in a rural community in northeastern Japan. Stroke 1998;29(8):1510-1518.

16. Egan BM, Zhao Y, Axon RN. US trends in prevalence, awareness, treatment, and control of hypertension, 1988-2008. JAMA 2010; 303(20):2043-2050.

17. Guo F, He D, Zhang W, Walton RG. Trends in prevalence, awareness, management, and control of hypertension among United States adults, 1999 to 2010. J Am Coll Cardiol 2012;60(7): 599-606.

18. Lee WY, Park JS, Noh SY, Rhee EJ, Kim SW, Zimmet PZ. Prevalence of the metabolic syndrome among 40,698 Korean metropolitan subjects. Diabetes Res Clin Pract 2004;65(2):143-149.

19. Ha YC, Chun HJ, Hwang HK, Kim BS, Kim JR. The prevalence, awareness, treatment, and control of hypertension, and related factors in rural Korea. Korean J Prev Med 2000;33(4):513520 (Korean).

20. Gu D, Reynolds K, Wu X, Chen J, Duan X, Muntner P, et al. The International Collaborative Study of Cardiovascular Disease in ASIA. Prevalence, awareness, treatment, and control of hypertension in china. Hypertension 2002;40(6):920-927.

21. Calhoun DA, Jones D, Textor S, Goff DC, Murphy TP, Toto RD, et al. Resistant hypertension: diagnosis, evaluation, and treatment. A scientific statement from the American Heart Association Professional Education Committee of the Council for High Blood Pressure Research. Hypertension 2008;51(6):1403-1419. 